Brit. Heart f., 1967, 29, 64.

\title{
Double Outlet Right Ventricle With Pulmonary Stenosis
}

\author{
M. K. A. DAYEM ${ }^{\star}$, L. PREGER $†$, J. F. GOODWIN, AND R. E. STEINER \\ From the Departments of Radiodiagnosis and Medicine (Clinical Cardiology), Postgraduate Medical School \\ and Hammersmith Hospital, London W.12
}

This paper reports five patients with the congenital cardiac anomaly of double outlet right ventricle and pulmonary stenosis, reviews the previously reported cases, and discusses the diagnostic features of the abnormality, especially with regard to the differential diagnosis from the tetralogy of Fallot.

The term double outlet right ventricle denotes that both the aorta and pulmonary artery have their origin wholly from the right ventricle. There may be no obstruction to the outflow tract of the right ventricle or there may be pulmonary infundibular or valvar stenosis, as in the five patients to be described. A ventricular septal defect provides the only route for blood to leave the left ventricle; there is therefore a left-to-right shunt at ventricular level. Double outlet right ventricle with pulmonary stenosis closely simulates the tetralogy of Fallot but the treatment differs. In the tetralogy of Fallot, radical surgical correction entails closure of the ventricular septal defect, in addition to resection of the pulmonary stenosis. The former would be lethal in double outlet right ventricle, where the ventricular septal defect is the only route by which the left ventricle can empty. The appropriate surgical treatment for the condition has been discussed by McGoon (1961) and Kirklin, Harp, and McGoon (1964). They described an operation in which a hammock-shaped prosthesis of ivalon, teflon, or pericardium is fashioned to seal off the ventricular septal defect from the right ventricle but at the same time to act as a conduit for blood to pass from the left ventricle via the partly closed

Received March 8, 1966.

* Holder of a Scholarship from the Government of the United Arab Republic.

† Holder of a Fellowship of the James Picker Foundation, in radiological research. Clinical Instructor in Radiology, University of California Hospitals, San Francisco. ventricular septal defect to the aorta. If the ventricular septal defect is very small, it may need enlargement. Pulmonary valvotomy and/or infundibular resection is performed to relieve the pulmonary stenosis.

All cases previously reported with clinical details are summarized in Tables I and III. Relatively few patients (about 34 in all) with double outlet right ventricle complicated by pulmonary stenosis have been previously recorded. Witham (1957) was the first to give this condition the name of double outlet right ventricle; he showed that cyanotic patients with this disorder could be divided into two subgroups depending on the site of obstruction to blood flow: those with pulmonary stenosis resembled the tetralogy of Fallot, while those with a high pulmonary vascular resistance and a right-toleft shunt simulated the Eisenmenger complex. Morgan et al. (1962) reported double outlet right ventricle with and without pulmonary stenosis, and used a similar classification as follows: Type 1 . Acyanotic. Type 2. Cyanotic: (2a) Fallot type (with pulmonary stenosis); (2b) Eisenmenger type (without pulmonary stenosis but with increased pulmonary arteriolar resistance).

Neufeld et al. (1961b) and Carey and Edwards (1965) in an analysis of their patients with double outlet right ventricle without pulmonary stenosis made a classification according to the site of the ventricular septal defect.

Type 1. There is an infracristal ventricular septal defect close to the aortic root and remote from the origin of the pulmonary artery. Most of the right ventricular blood passes into the pulmonary artery, and most of the left ventricular outflow passes directly to the aorta. These patients are thus acyanotic unless their condition is complicated by pulmonary stenosis or by severe pulmonary 
Type 2a. These patients have a supracristal ventricular septal defect which lies near to the pulmonary artery and is relatively remote from the aortic orifice. Flow from the right ventricle is mainly into the aorta, and these patients are cyanotic from birth.

Type $2 b$. Here there is a large supracristal ventricular septal defect related to both the aortic and pulmonary artery orifices. Flow from the right ventricle is into both great vessels. There was one patient only in this group who was cyanosed. Neufeld, DuShane, and Edwards (1961a), and Carey and Edwards (1965) have not reported extensively on patients with double outlet right ventricle with pulmonary stenosis, but in an analysis of six such patients (Neufeld et al., 1961a), all had an infracristal ventricular septal defect together with infundibular stenosis created by the vertical limb of the crista supraventricularis. All patients were cyanosed from birth, or soon after.

Carey and Edwards (1965) suggest that a main feature of double outlet right ventricle, with or without pulmonary stenosis, is the separation of the aortic and mitral valve rings by a ridge of muscular tissue. In normal patients, or patients with the tetralogy of Fallot and those with simple ventricular septal defect, the two valve rings are in continuity with the cardiac fibrous skeleton. These same authors also state that in double outlet right ventricle with pulmonary stenosis the parietal band of the crista supraventricularis is enlarged and very prominent when seen in angiocardiograms in the antero-posterior projection. They also make several observations on the position of the semilunar valves, the appearance of the crista, and the inclination of the ascending aorta in the lateral projection on angiocardiography. These further points are discussed later in the present paper.

\section{Patients and Methods}

Five patients having double outlet right ventricle with pulmonary stenosis were studied (Tables I, II, and III). In each case the diagnosis was suspected on clinical, cardiographic, and hæmodynamic grounds and confirmed by angiocardiography. In one patient cardiotomy was performed, the patient died subsequently and the diagnosis was proved at necropsy. In addition, all the published cases of double outlet right ventricle with pulmonary stenosis in which clinical data were reported are analysed and compared with our series. Two patients with double right ventricle with pulmonary stenosis who have been previously diagnosed at this hospital and reported by Morgan et al. (1962) are included.

In order to detect the characteristic angiocardiographic signs of double outlet right ventricle with pulmonary stenosis, we reviewed all the recent angiocardiographic examinations on patients with the clinical diagnosis of tetralogy of Fallot in this hospital. This series comprised 120 patients in whom angiocardiography was performed between 1962 and 1965. This survey was performed because patients with double outlet right ventricle with pulmonary stenosis may easily be confused with patients with the tetralogy of Fallot

TABLE I

CLINICAL FINDINGS IN 20 PATIENTS WITH DOUBLE OUTLET RIGHT VENTRICLE WITH PULMONARY STENOSIS

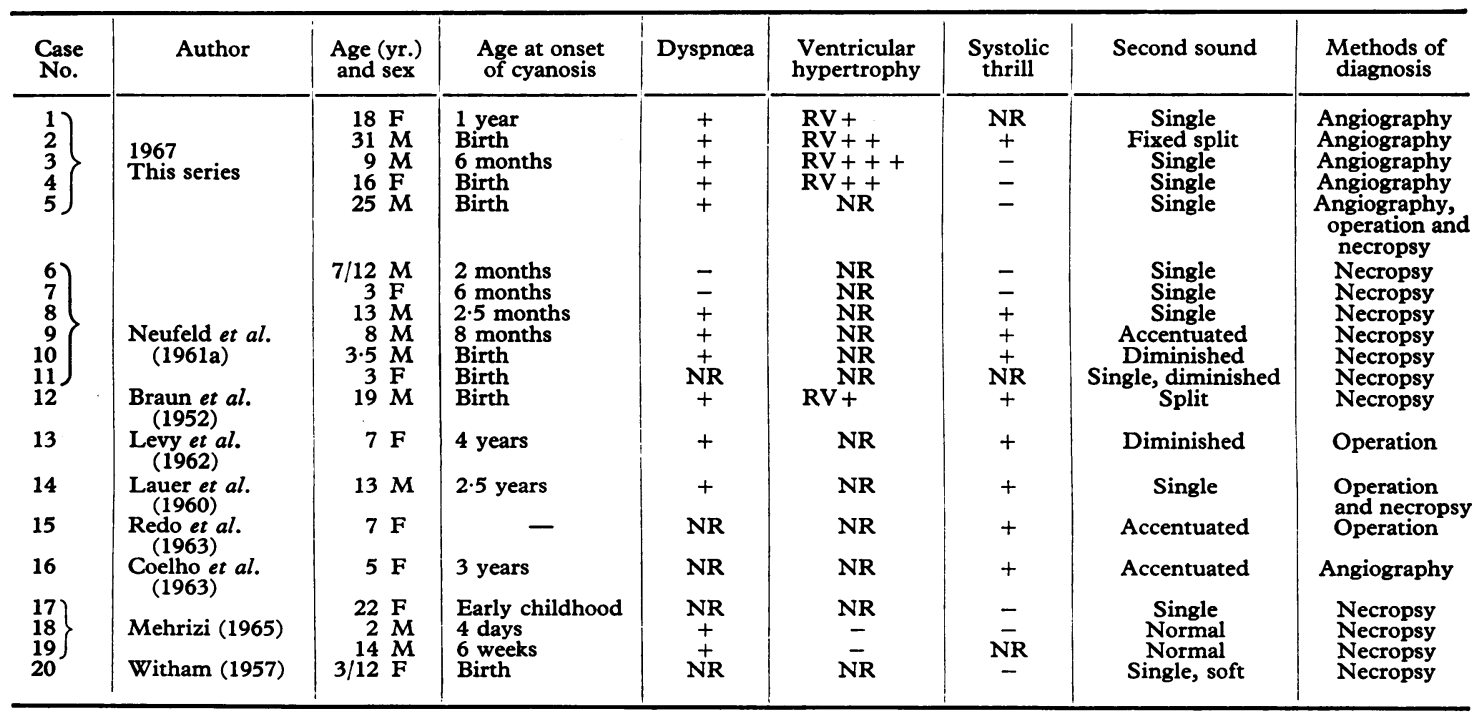

- , Absent; NR, not recorded; +, present. 
TABLE II

SUMMARY OF ANGIOCARDIOGRAPHIC FINDINGS IN PATIENTS WITH DOUBLE OUTLET RIGHT VENTRICLE WITH PULMONARY STENOSIS (PRESENT SERIES)

\begin{tabular}{|c|c|c|c|c|c|c|c|c|c|c|}
\hline $\begin{array}{l}\text { Case } \\
\text { No. }\end{array}$ & \multicolumn{2}{|c|}{$\begin{array}{l}\text { Age (yr.) } \\
\text { and sex }\end{array}$} & $\begin{array}{c}\text { Relation of aorta } \\
\text { and pulmonary } \\
\text { artery on lateral } \\
\text { view } \\
\text { angiocardiogram }\end{array}$ & $\begin{array}{c}\text { Parietal band } \\
\text { enlargement } \\
\text { on antero- } \\
\text { posterior } \\
\text { angiocardio- } \\
\text { gram }\end{array}$ & $\begin{array}{c}\text { Level of } \\
\text { aortic and } \\
\text { pulmonary } \\
\text { artery valve } \\
\text { rings }\end{array}$ & $\begin{array}{l}\text { Pulmonary } \\
\text { stenosis }\end{array}$ & $\begin{array}{c}\text { Relative } \\
\text { density of } \\
\text { great } \\
\text { vessels }\end{array}$ & $\begin{array}{l}\text { Ratio of } \\
\text { width of } \\
\text { pulmonary } \\
\text { artery and } \\
\text { aorta on } \\
\text { antero- } \\
\text { posterior } \\
\text { view }\end{array}$ & $\begin{array}{c}\text { First great } \\
\text { vessel to } \\
\text { opacify }\end{array}$ & Proof \\
\hline 1 & 18 & $F$ & $\begin{array}{l}\text { Aotra slightly } \\
\text { anterior to } \\
\text { pulmonary } \\
\text { artery }\end{array}$ & + & Same level & $\begin{array}{l}\text { Infundibular } \\
\text { and valvar }\end{array}$ & Equal & 0.9 & $\begin{array}{l}\text { Pulmonary } \\
\text { artery }\end{array}$ & $\begin{array}{l}\text { Angiocardio- } \\
\text { graphy }\end{array}$ \\
\hline 2 & 31 & $\mathbf{M}$ & $\begin{array}{l}\text { Aorta slightly } \\
\text { anterior to } \\
\text { pulmonary } \\
\text { artery }\end{array}$ & + & Same level & $\begin{array}{c}\text { Infundibular } \\
\text { and valvar }\end{array}$ & $\begin{array}{c}\text { Pulmonary } \\
\text { artery } \\
\text { denser } \\
\text { than aorta }\end{array}$ & 0.9 & $\begin{array}{l}\text { Pulmonary } \\
\text { artery }\end{array}$ & $\begin{array}{c}\text { Angiocardio- } \\
\text { graphy }\end{array}$ \\
\hline 3 & 9 & $\mathbf{M}$ & $\begin{array}{l}\text { Aorta slightly } \\
\text { posterior to } \\
\text { pulmonary } \\
\text { artery }\end{array}$ & + & $\begin{array}{l}\text { Pulmonary } \\
\text { artery } \\
\text { valve } \\
1 \mathrm{~cm} . \\
\text { higher } \\
\text { than } \\
\text { aortic } \\
\text { valve ring }\end{array}$ & $\begin{array}{l}\text { Infundibular } \\
\text { and valvar }\end{array}$ & Equal & 0.7 & $\underset{\text { taneous }}{\text { Simul- }}$ & $\begin{array}{l}\text { Angiocardio- } \\
\text { graphy }\end{array}$ \\
\hline 4 & 16 & $\mathbf{F}$ & $\begin{array}{l}\text { Dextrocardia; } \\
\text { aorta slightly } \\
\text { anterior to } \\
\text { pulmonary } \\
\text { artery }\end{array}$ & + & $\begin{array}{l}\text { Aortic valve } \\
\text { ring } 3 \mathrm{~cm} \text {. } \\
\text { lower } \\
\text { than } \\
\text { pulmon- } \\
\text { ary artery } \\
\text { valve ring }\end{array}$ & Infundibular & $\begin{array}{l}\text { Initially } \\
\text { equal, on } \\
\text { recircula- } \\
\text { tion aorta } \\
\text { denser } \\
\text { than pul- } \\
\text { monary }\end{array}$ & 0.8 & $\underset{\text { taneous }}{\text { Simul- }}$ & $\begin{array}{l}\text { Angiocardio- } \\
\text { graphy }\end{array}$ \\
\hline 5 & 25 & $\mathbf{M}$ & $\begin{array}{l}\text { Aorta and pul- } \\
\text { monary artery } \\
\text { overlap }\end{array}$ & + & Same level & Infundibular & $\begin{array}{l}\text { artery } \\
\text { Pulmonary } \\
\text { artery }\end{array}$ & $\begin{array}{l}\text { Could not } \\
\text { be } \\
\text { assessed }\end{array}$ & $\begin{array}{l}\text { Could not } \\
\text { be } \\
\text { assessed }\end{array}$ & Necropsy \\
\hline
\end{tabular}

with marked aortic override whom they so closely resemble.

The initial procedure was to select the angiocardiograms showing pulmonary stenosis, a ventricular septal defect, and marked aortic override. This group included patients with double outlet right ventricle and pulmonary stenosis, and also those patients with the tetralogy of Fallot who most resembled double outlet right ventricle with pulmonary stenosis. An important sign required for acceptance of patients as having double outlet right ventricle with pulmonary stenosis was that the ascending aorta as seen on the lateral angiocardiogram had to be directed inferiorly and anteriorly towards the right ventricle, and not posteriorly and inferiorly towards the left ventricle as in normal patients and most of those with the tetralogy of Fallot. Furthermore, the

TABLE III

HAMODYNAMIC FINDINGS IN 12 PATIENTS WITH DOUBLE OUTLET RIGHT VENTRICLE WITH PULMONARY STENOSIS

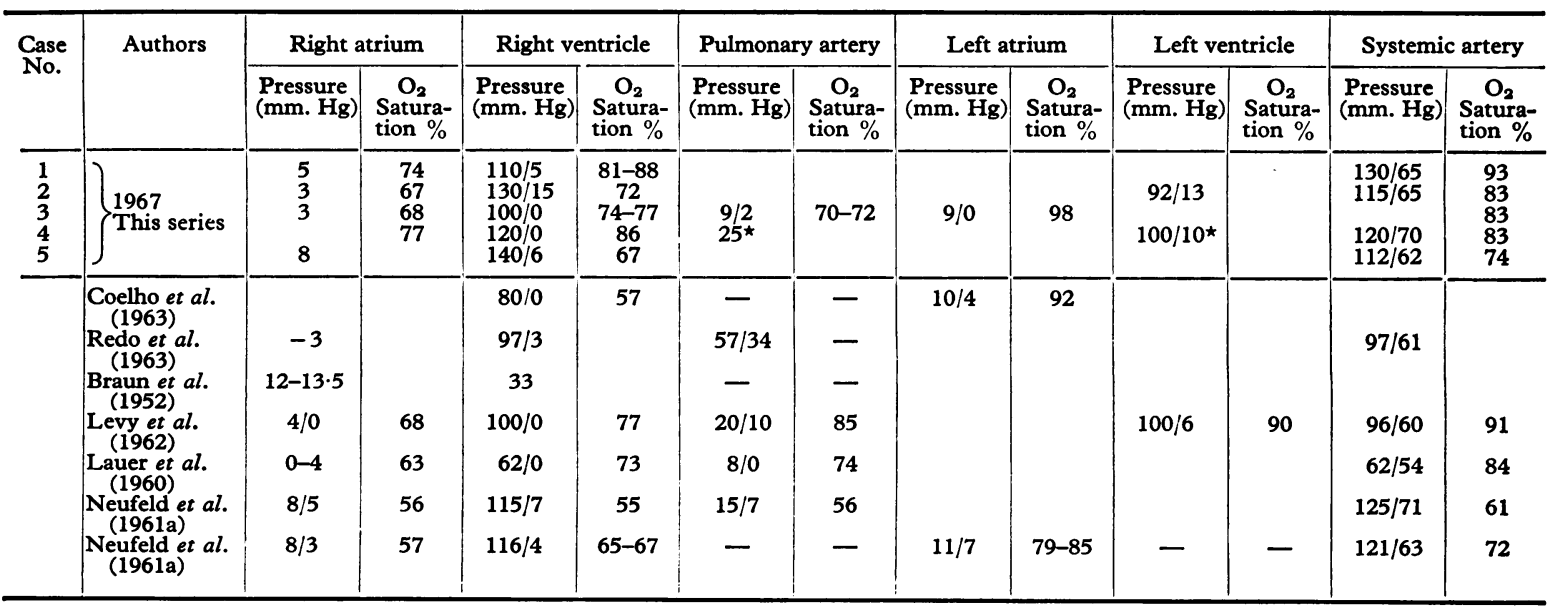

$\star$ At operation. 

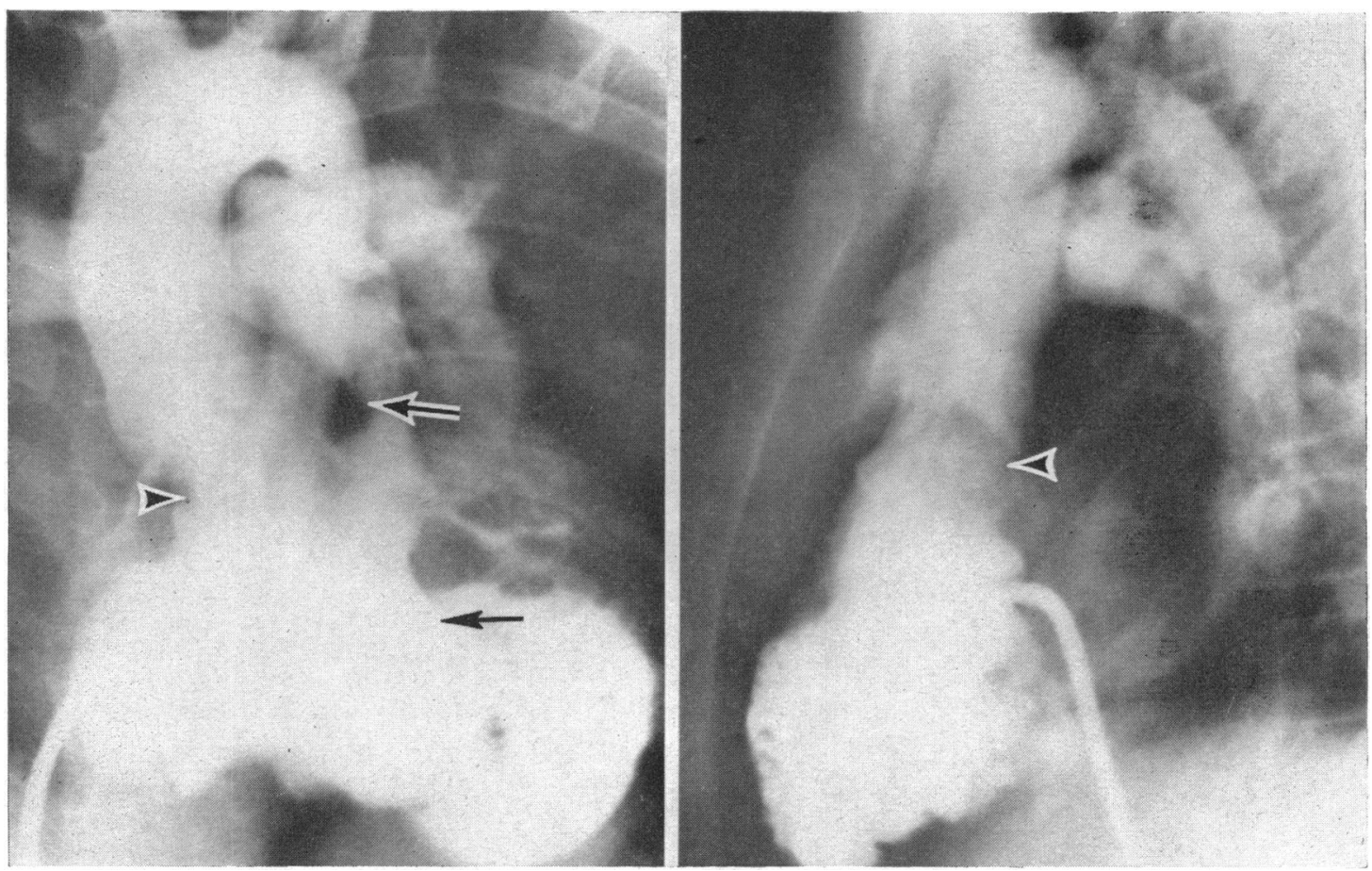

FIG. 1.-Angiocardiogram, right ventricular injection. Antero-posterior and lateral views of a patient (Case 3) with double outlet right ventricle with pulmonary stenosis (infundibular and valvar). $\leftarrow$ (higher arrow) indicates abnormally prominent parietal band of crista supraventricularis. indicates high aortic valve position. Catheter tip lies in the ventricular septal defect to opacify left ventricle (lower arrow $\leftarrow$ indicates tip of catheter).

non-coronary cusp of the aortic valve had to be in front of the plane of the ventricular septum. The relation of the walls of the pulmonary artery and aorta, and in addition the ratio of the width of the pulmonary artery to the width of the aorta, was measured in the lateral angiocardiogram. The aortic width was measured above the level of the sinuses of Valsalva, and the pulmonary artery width was measured beyond an area of post-stenotic dilatation where its calibre had become uniform. Similar measurements were made in 12 patients with a typical appearance of the tetralogy of Fallot, to provide a basis for comparison.

Angiocardiograms so selected were then subjected to an examination of the crista supraventricularis and the position of the semilunar valves. The patients were divided into two groups; those in whom the crista supraventricularis could be more easily identified in the lateral projection and those in whom it could only be identified in the antero-posterior projection. The former group were considered as typical examples of the tetralogy of Fallot, and surgical proof of this diagnosis was available in the large majority. The latter group, following the work of Carey and Edwards (1965), were considered as potential cases of double outlet right ventricle with pulmonary stenosis. The crista was identified in the antero-posterior projection as a non-opacified tongue-like area lying between the aorta and the pulmonary artery in a medial relation with the infundibular portion of the right ventricular outflow tract (Fig. 1, 2, 7, 10, and 11). An assessment of the position of the semilunar valves relative to each other on the antero-posterior and lateral projections was made (Fig. 2). The level of the valve ring was chosen rather than the valve cusps, since varying degrees of doming of the pulmonary cusps in those patients with valvular stenosis made comparison of the levels of the cusps difficult. In the lateral projection the most inferior level of the aortic and pulmonary sinuses was taken as the level of the valve rings (A. Rudhe, 1964, personal communications). Because of the aortic valve obliquity in the antero-posterior projection, its mid-point was taken in the comparison of aortic and pulmonary valve levels.

The width of the pulmonary artery and aorta was measured in the antero-posterior projection.

In an attempt to assess the degree of shunting, the relative degree of opacification in the great vessels, and the time sequence of opacification were noted.

\section{RESULTS}

Clinical Findings. In Table I the main clinical findings in 15 patients with double outlet right ventricle with pulmonary stenosis, previously reported, are summarized, together with our five patients. 


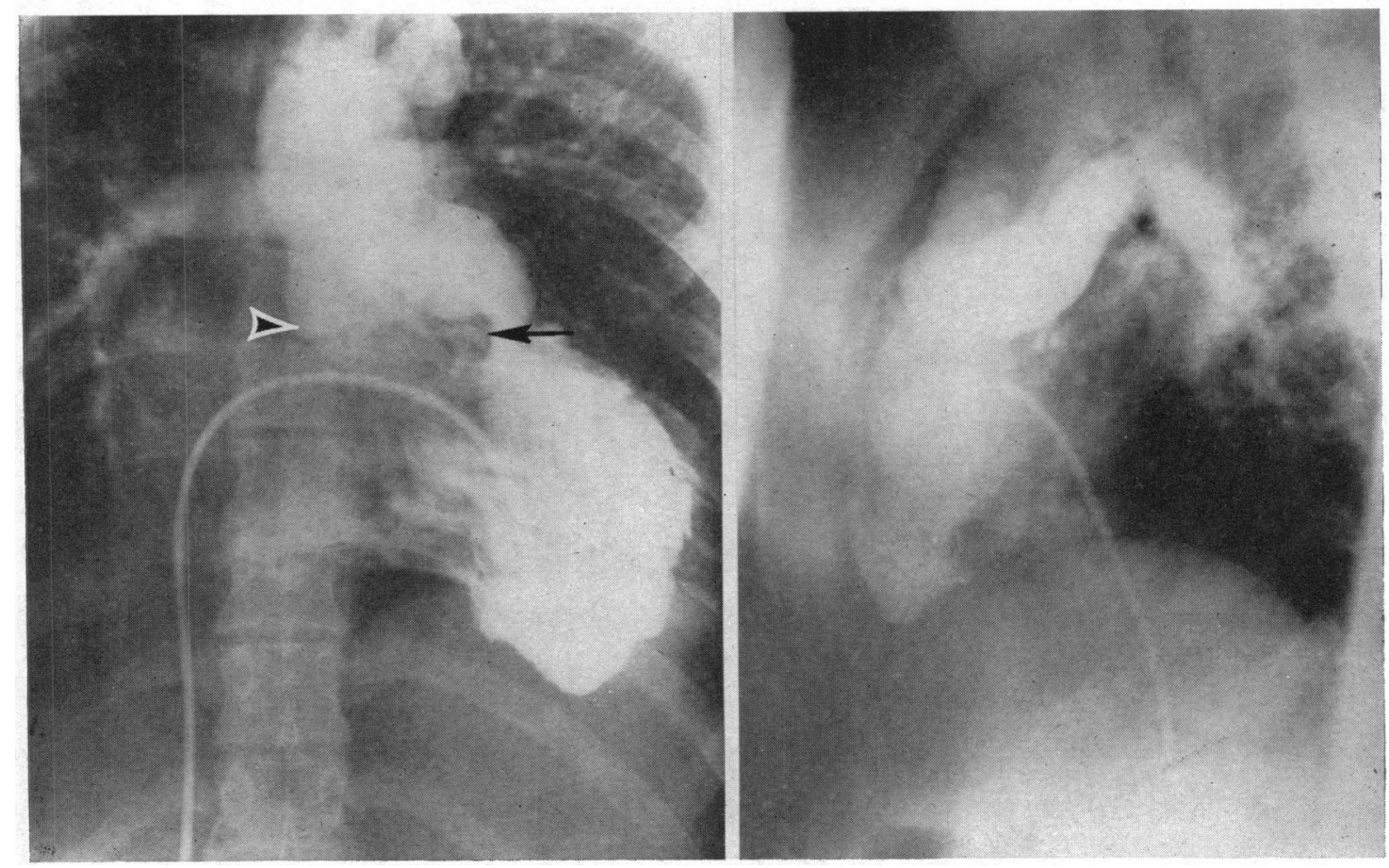

FIG. 2.-Angiocardiogram, right ventricular injection. Antero-posterior and lateral views of Case 1 with double outlet right ventricle with pulmonary stenosis (infundibular and valvar). Aortic and pulmonary valves lie at the same level in antero-posterior projection. The origin of both great vessels from the opacified right ventricle is seen in the lateral projection. $(\leftarrow)$ Prominent parietal band is seen in the antero-posterior projection. Previous subclavian-pulmonary artery anastomosis. $\rightarrow$ indicates the level of aortic and pulmonary valves.

The male-to-female ratio was 1.5:1 in our cases and in those reported by others, and the ages ranged between 3 months and 31 years with a mean of 11.0 years. Shortness of breath was present in all our patients with double outlet right ventricle and pulmonary stenosis, and in 14 of the 15 patients reported previously. Cyanosis was found at birth or developed during the first year of life in all our 5 patients. The majority of the patients previously reported had a similar early onset of cyanosis. The intensity of cyanosis progressively decreased in 3 of our patients, being minimal in late childhood. Four of our own patients and 5 reported in other series had clubbing of the fingers and toes.

Squatting, which has previously been recorded infrequently in double outlet right ventricle with pulmonary stenosis, was recorded in all our patients, and was frequent in 3. Cyanotic attacks were present infrequently.

The arterial pulse was usually normal in character in our patients. In 2, however, the left radial pulse was absent due to a previous subclavianpulmonary artery anastomosis. Right ventricular hypertrophy was detected in all our patients. A systolic thrill was felt in only one patient in our series. It was present, however, in more than half the patients previously described. All our patients had grade $3 / 4$ ejection systolic murmurs maximal along the left sternal border, between the second and the fourth intercostal spaces. A similar murmur was heard in nearly all the cases previously reported. This murmur was holosystolic in quality in the cases reported by Levy et al. (1962) and by Redo et al. (1963). The second heart sound was well heard and was single in most patients. Only one of our cases had duplication of the second pulmonary sound, similar to the patient reported by Braun et al. (1952). The site where the second heart sound is maximally heard was reported to be of importance in differentiating Fallot's tetralogy from transposition of the great vessels (Nadas, 1963). This was carefully noted in 4 of our patients: in 2 this sound was best heard in the second space close to the left sternal edge, as in transposition of the great arteries; in the other 2 the second heart sound was heard better in the fourth left intercostal space, as in the tetralogy of Fallot.

Other auscultatory signs were caused by addit- 
ional lesions. For example, a continuous murmur was heard in our patients who had been previously submitted to a subclavian-pulmonary artery anastomosis. An early diastolic murmur was heard in the patient reported by Levy et al. (1962) who had, in addition to double outlet right ventricle with pulmonary stenosis, a bicuspid aortic valve and aortic incompetence.

The jugular venous pulse was normal in 3 of our patients and slightly raised in 2 .

Electrocardiogram. In our 5 patients the electrical axis of the hearts in the frontal plane was $+120^{\circ},+120^{\circ},+130^{\circ},+165^{\circ}$ respectively in 4 , and in the patient with dextrocardia it was $+40^{\circ}$. The $P$ wave was high and peaked in 3 patients, indicating right atrial hypertrophy, and also bifid in one, indicating biatrial hypertrophy. Partial right bundle-branch block was found in one patient and a prolonged $P-R$ interval in another.

Right axis deviation was not common in the cases previously reported. Seven patients had, instead, left axis deviation (Neufeld et al., 1961a, b; Lauer, DuShane, and Edwards, 1960; Witham, 1957; Mirowski, Mehrizi, and Taussig, 1963), which accounts for 18 per cent of all cardiograms reported in this condition. Mirowski et al. (1963) analysed a series of 22 cardiograms of patients with double outlet right ventricle with pulmonary stenosis, and noted the frequency of left ventricular hypertrophy (74\%), prolonged $\mathrm{P}-\mathrm{R}$ interval (grade 1 heart block) $(60 \%)$, and partial right bundle-branch block (63\%). Other cases with left ventricular hypertrophy and partial right bundle-branch block were reported by Levy et al. (1962) and Braun et al. (1952).

Radiological Examination (plain films). The peripheral pulmonary arterial vascular pattern was normal in 4 patients in whom a plain film was available, though 2 of them had had a previous subclavian-pulmonary artery anastomosis. In 3 patients there was evidence of right ventricular enlargement in the lateral film (Fig. 3). In 2 patients the cardiac configuration suggested the tetralogy of Fallot in the postero-anterior projection (Fig. 3 and 4). In one (Case 1, Fig. 5) who previously had had a subclavian-pulmonary artery anastomosis, there was evidence of generalized cardiac enlargement. In one patient the appearances were normal (Fig. 6).

Hamodynamics. There have been earlier reports of cardiac catheterization data in 7 patients with double outlet right ventricle with pulmonary stenosis, and catheterization was performed in all our patients. The findings in the fully reported cases are shown in Table III. The right atrial pressure and oxygen saturation were generally within normal limits. The right ventricular pressure was always raised to systemic levels, and the mean systolic pressure was $100 \mathrm{~mm}$. $\mathrm{Hg}$ for all the patients. There was an increase in the oxygen saturation in the right ventricle compared with the saturation in the right atrium in 4 . The same

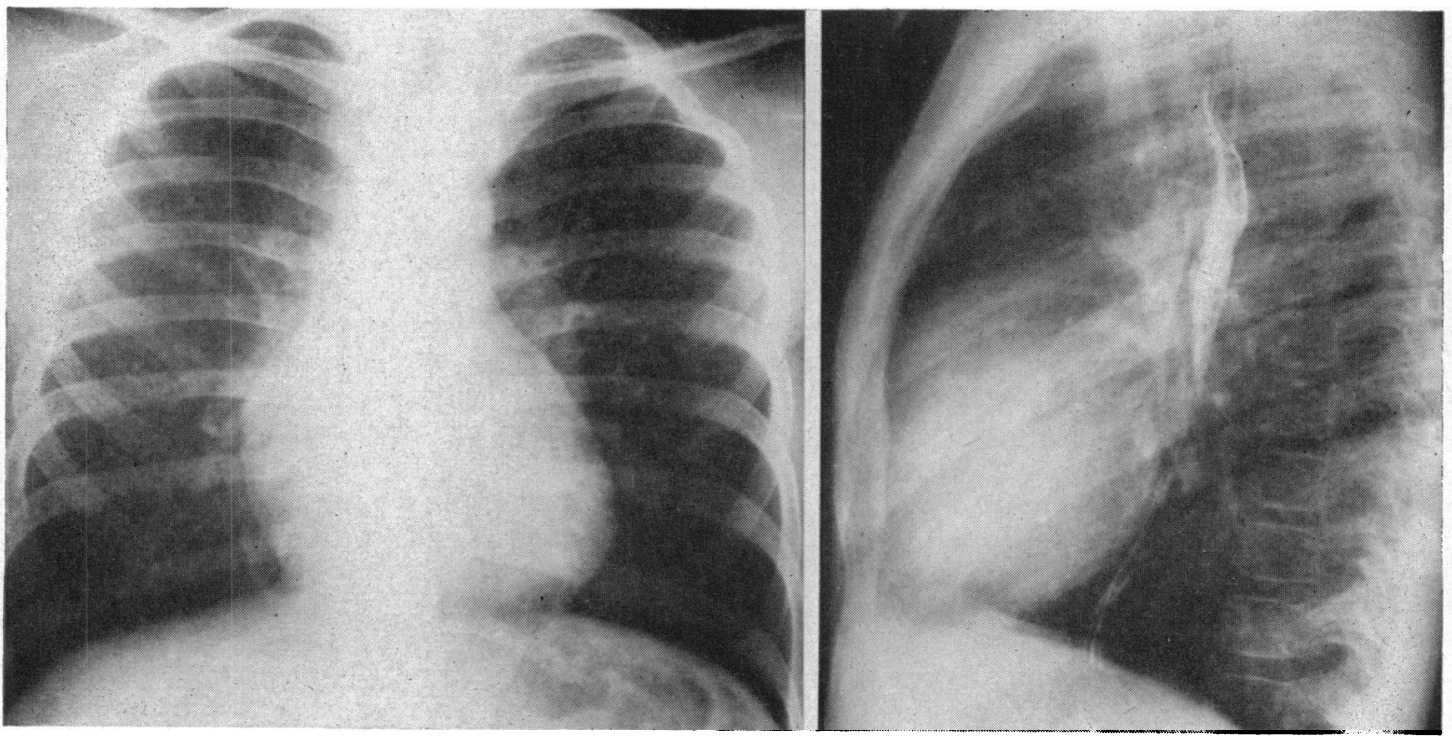

Fig. 3.-Chest radiograph. Postero-anterior and lateral views of Case 3 with double outlet right ventricle with pulmonary stenosis simulating the tetralogy of Fallot, with large right ventricle and broad aortic silhouette but fairly normal peripheral pulmonary arterial pattern. 

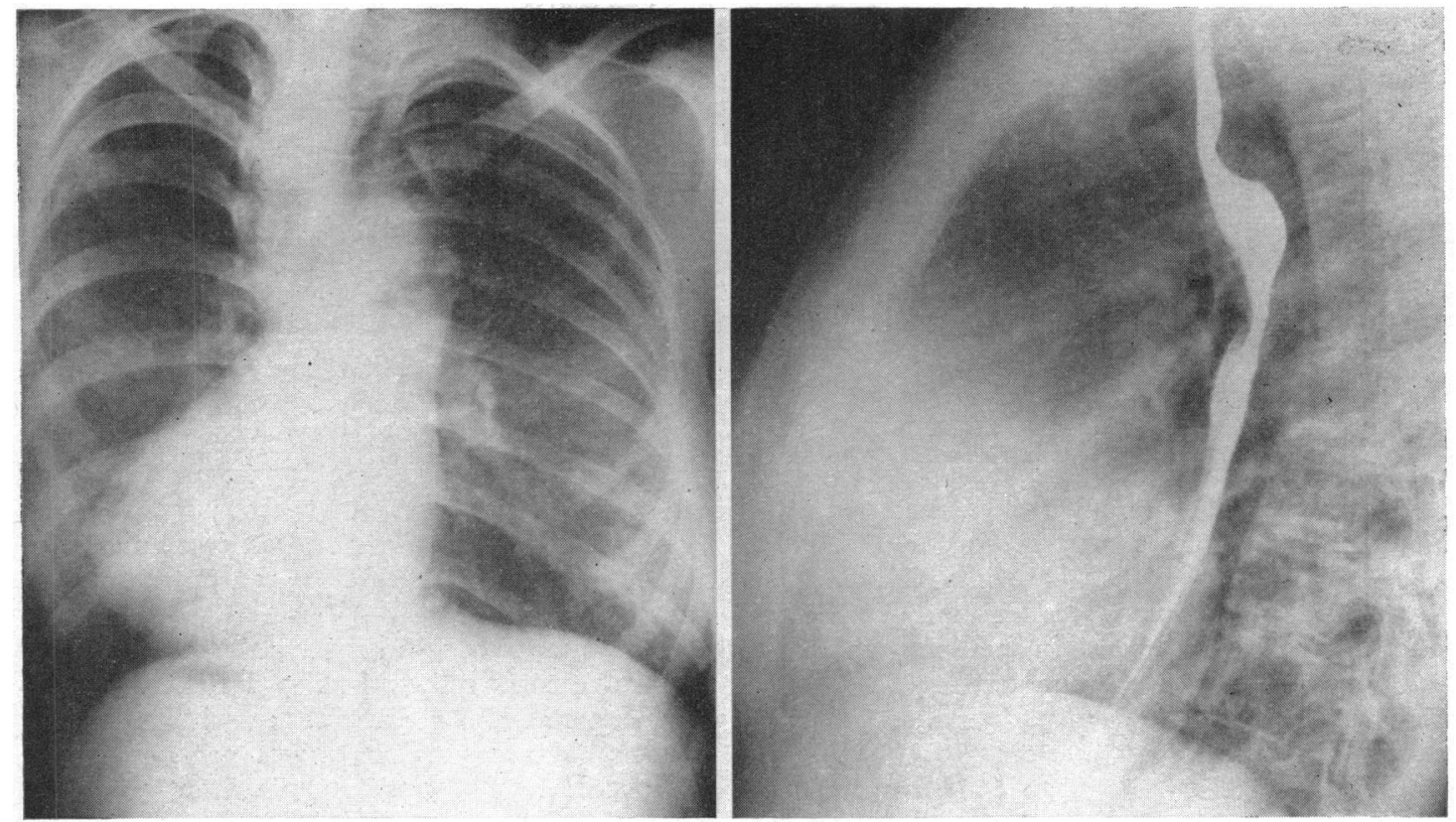

Fig. 4.-Chest radiograph. Postero-anterior and lateral views of Case 4, with double outlet right ventricle with pulmonary stenosis. Cardiomegaly present. Right ventricular outflow tract is normal. Pulmonary arterial vascular pattern is normal. Previous subclavian-pulmonary artery anastomosis. Dextrocardia. Situs inversus.

observation was found in 4 of the patients previously reported. This is due to the total shunt of the left ventricular output through the ventricular septal defect into the right ventricle. The increase ranged from 5 to 14 per cent in our patients and from 8 to 10 per cent in the earlier group.

The catheter could not be introduced into the pulmonary artery in 4 of our patients and in 6 patients previously reported. In the patients in whom the pulmonary valve was crossed, the pressure gradient ranged from 40 to $100 \mathrm{~mm}$. $\mathrm{Hg}$ with a mean of $77 \mathrm{~mm}$. $\mathrm{Hg}$. The pulmonary artery pressure varied from $8 / 0$ to $57 / 34 \mathrm{~mm}$. $\mathrm{Hg}$. In one patient reported by Levy et al. there was a further increase in the oxygen saturation in the pulmonary artery of about 8 per cent: this might be due to the incomplete mixing of the blood derived from the systemic and pulmonary venous returns in the right ventricle. The arterial pressure was usually equal to the right ventricular pressure, and the arterial oxygen saturation varied between 61 and 93 per cent. The left atrium was entered once in our series and in the cases reported by Coelho et al. (1963)' and Neufeld et al. (1961a). In our patients the left atrial pressure and oxygen saturation were normal. In those reported earlier, the left atrial pressure was normal, but the oxygen saturation was reduced, possibly due to a right-toleft shunt across the atrial septum.
In no case was the left ventricular pressure significantly higher than the right ventricular pressure when both were measured simultaneously.

Angiocardiography. In the 5 patients considered to have a double outlet right ventricle the angiocardiogram showed that, in addition to the basic defect of ventricular septal defect with pulmonary stenosis, the origins of the great vessels overlay each other and were placed in the same coronal plane. Both the aorta and the pulmonary artery appeared to arise from the right ventricle and were opacified from this chamber. The essential diagnostic criteria for double outlet right ventricle were thus fulfilled.

The degree of forward displacement of the aorta was variable: in all patients the right posterior (non-coronary) cusp lay at or anterior to the plane of the interventricular septum. In 2 patients (Cases 1 and 2) the anterior wall of the aorta lay slightly anterior to the anterior wall of the pulmonary artery. In one (Case 5) there was superimposition of the anterior wall of the aorta and pulmonary artery, and in another (Case 4) there was dextrocardia, with both great vessels arising from the anterior ventricle, the aorta being slightly anterior to the pulmonary artery (Fig. 4).

In 3 patients (Cases 1,2, and 5) the semilunar valves of the aorta and pulmonary artery lay at the same cross-sectional level as judged on antero- 


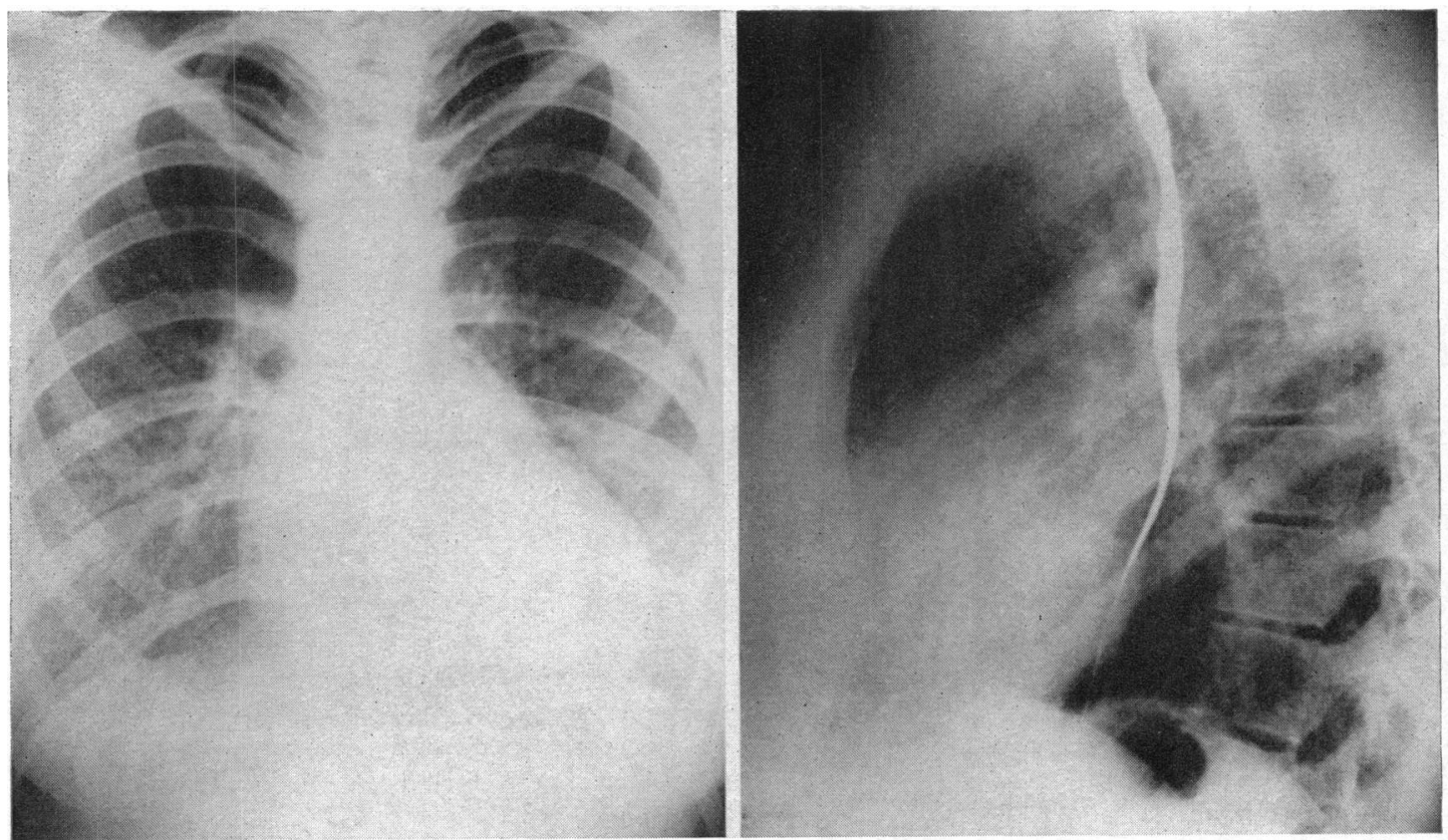

FIG. 5.-Chest radiograph. Postero-anterior and lateral view of Case 1, with double outlet right ventricle with pulmonary stenosis. Cardiomegaly present. Right ventricular outflow tract is normal. Pulmonary arterial vascular pattern is normal. Previous subclavian-pulmonary artery anastomosis.

posterior and lateral films. In 2 (Cases 3 and 4 ) the pulmonary valve lay superior to the aortic valve by $1 \mathrm{~cm}$. and $3 \mathrm{~cm}$., respectively. In all 5 patients the parietal band of the crista supraventricularis was seen prominently in the antero-posterior projection, but not at all in the lateral projection (Fig. 1, 2, 7, 10 , and 11).

The sequence of opacification of the great vessels,

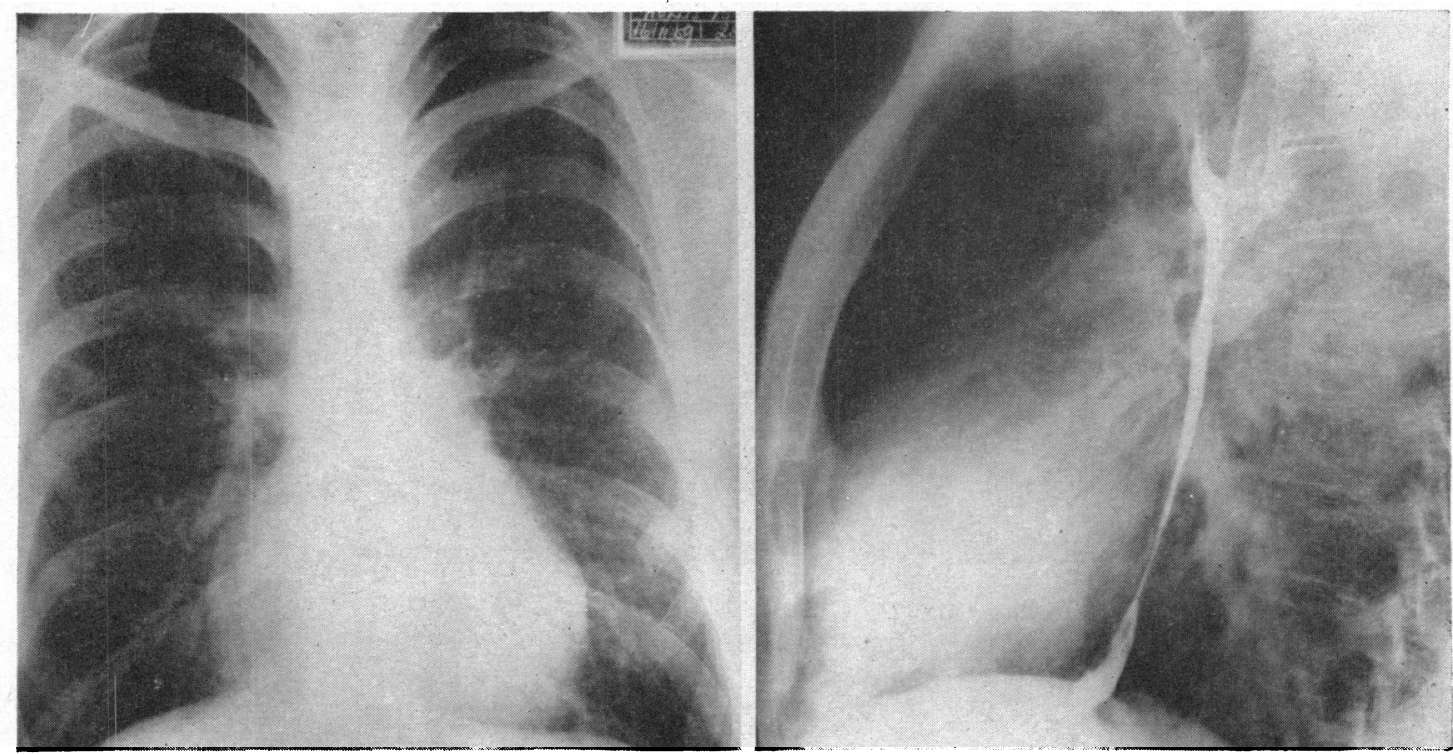

FIG. 6.-Chest radiograph. Postero-anterior and lateral view of Case 5, with double outlet right ventricle with pulmonary stenosis. Appearance is normal. 


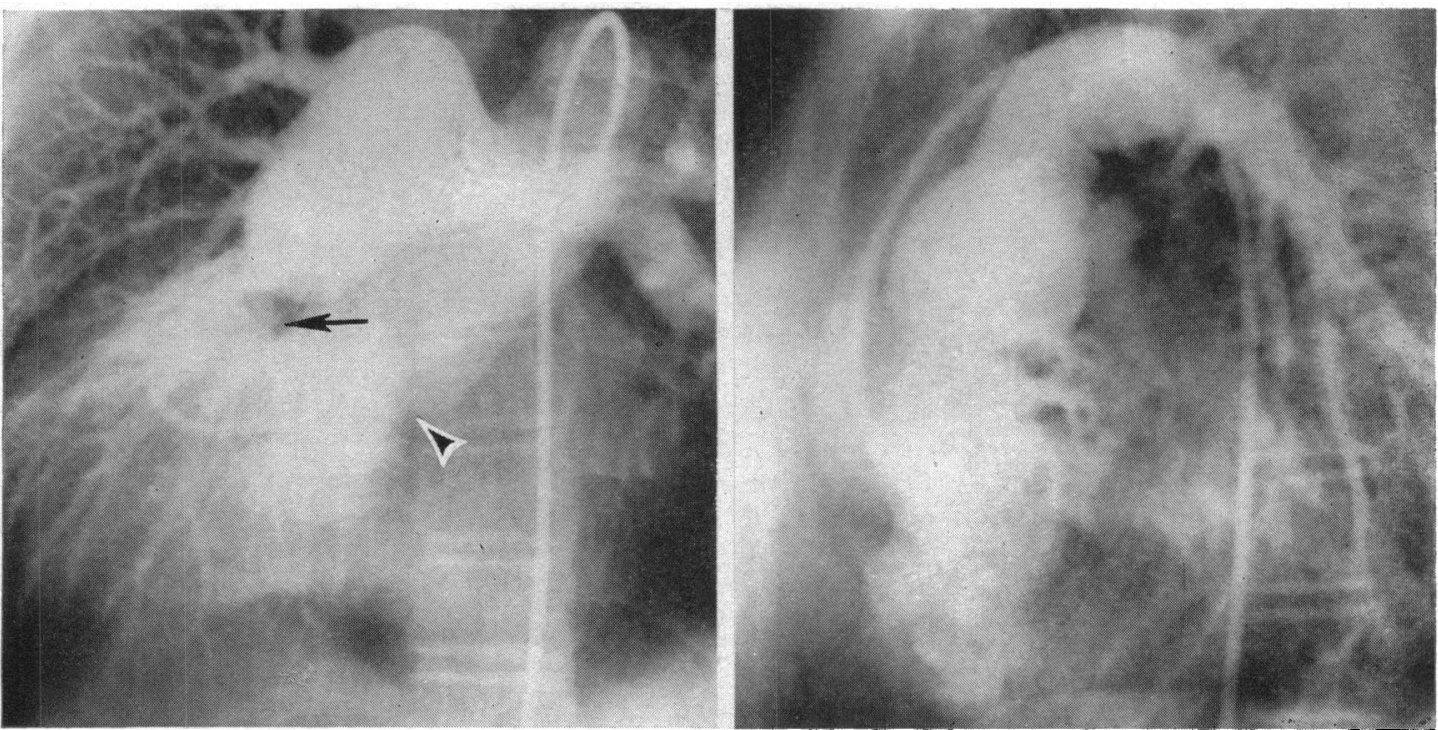

Fig. 7.-Angiocardiogram, right ventricular injection via femoral artery and aorta. Antero-posterior and lateral view of Case 4 with double outlet right ventricle with pulmonary stenosis. There is dextrocardia and transposition of the great vessels, the aorta lying anteriorly and to the left of the pulmonary artery. Parietal band $\leftarrow$ and aortic valve $\varangle$ are indicated. Previous pulmonary valvotomy and subclavian-pulmonary artery anastomosis.

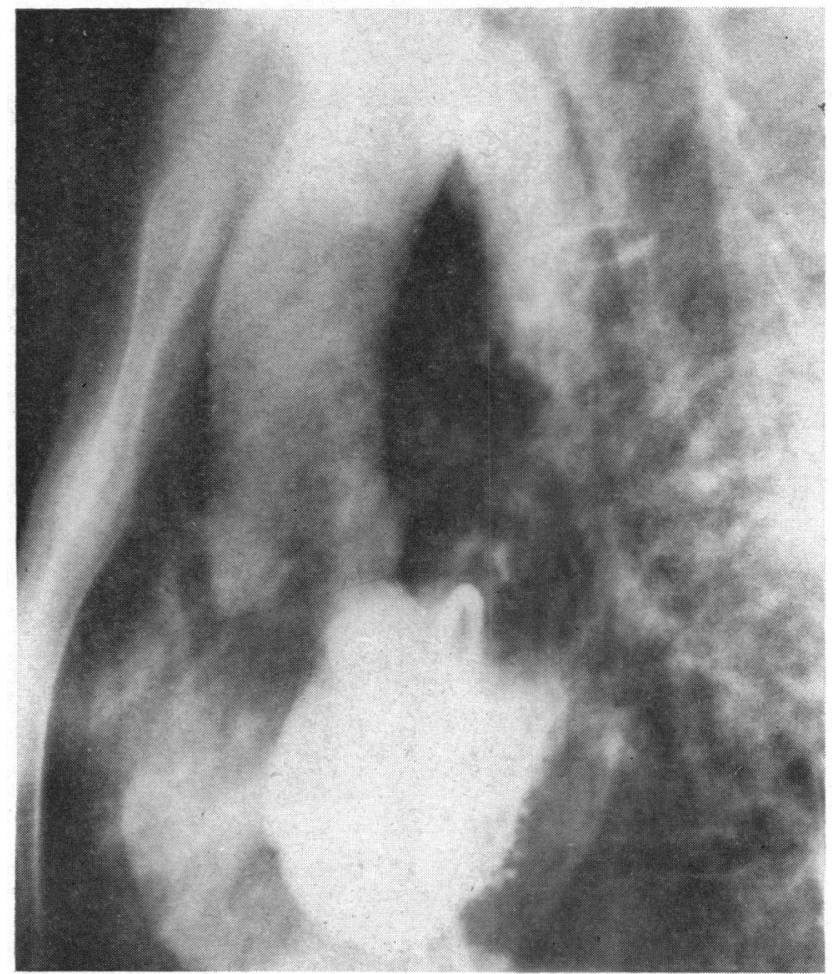

FIG. 8.-Angiocardiogram, left ventricular injection via atrial septal defect. Lateral view of a patient with the tetralogy of Fallot. Most of aortic root overlies the right ventricle. The inclination of the aortic root is more anterior than usual, but is not so anterior as in double outlet right ventricle (cf. Fig. 1). 
their relative densities, and the ratio of the width of the pulmonary artery to the width of the aorta are shown in Table II. The ratio of the width of the pulmonary artery to the width of the aorta varied from $0 \cdot 7-0.9$.

\section{Discussion}

Proper recognition of the double outlet right ventricle with pulmonary stenosis is essential for successful surgery, for the surgical treatment of this entity differs from that required for Fallot's tetralogy. Failure to recognize this congenital abnormality at the time of operation, or ignorance of its existence, has led to inappropriate closure of the ventricular septal defect, with fatal results due to obstruction of the only exit from the left ventricle (Redo et al., 1963; Engle et al., 1960).

Differentiation on a clinical basis alone is difficult. The early onset of cyanosis and significant degree of shortness of breath should, however, draw attention to the possibility of double outlet right ventricle with pulmonary stenosis. The site of maximum intensity of aortic closure in the 2nd intercostal space is a valuable clue, but maximum intensity in the 4th space does not preclude the diagnosis.

Another clue to the diagnosis may be derived from the electrocardiogram. There may be evidence of slight left ventricular hypertrophy, prolonged P-R interval, or right bundle-branch block

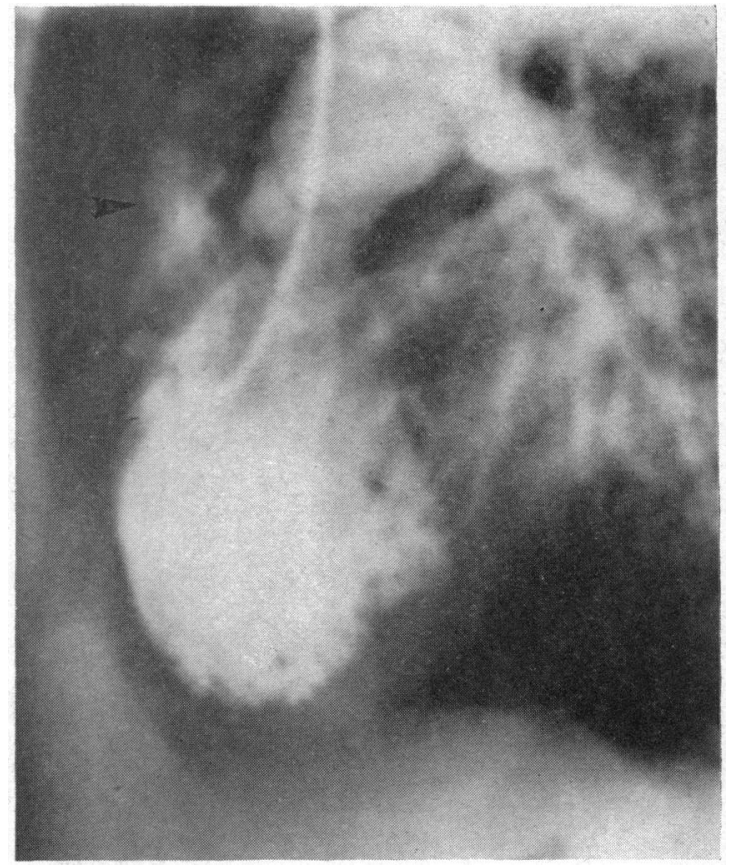

FIG. 9.-Angiocardiogram, injection into common ventricle, morphologically left, right ventricle is rudimentary. Lateral view of a patient with transposition of the great vessels. Aortic valve is at high level. $\rightarrow$ Points to the level of the aortic valve.

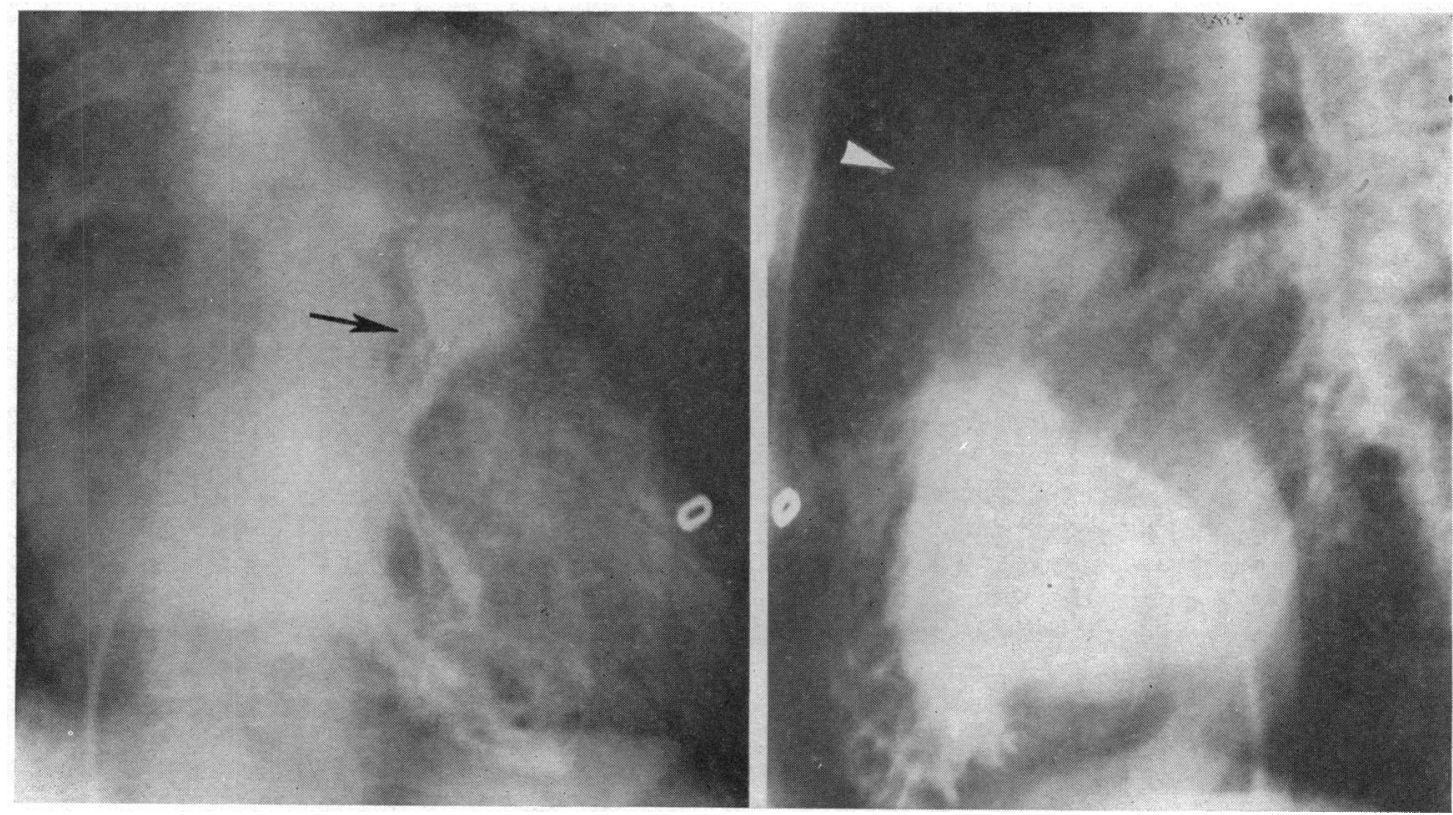

FIG. 10.-Angiocardiogram, right ventricular injection. Antero-posterior and lateral view of Case 2 with double outlet right ventricle with pulmonary stenosis. Anterior wall of the aorta (white arrow head) lies slightly anterior to anterior wall of pulmonary artery. Prominent parietal band of the crista supraventricularis $(\rightarrow)$. 


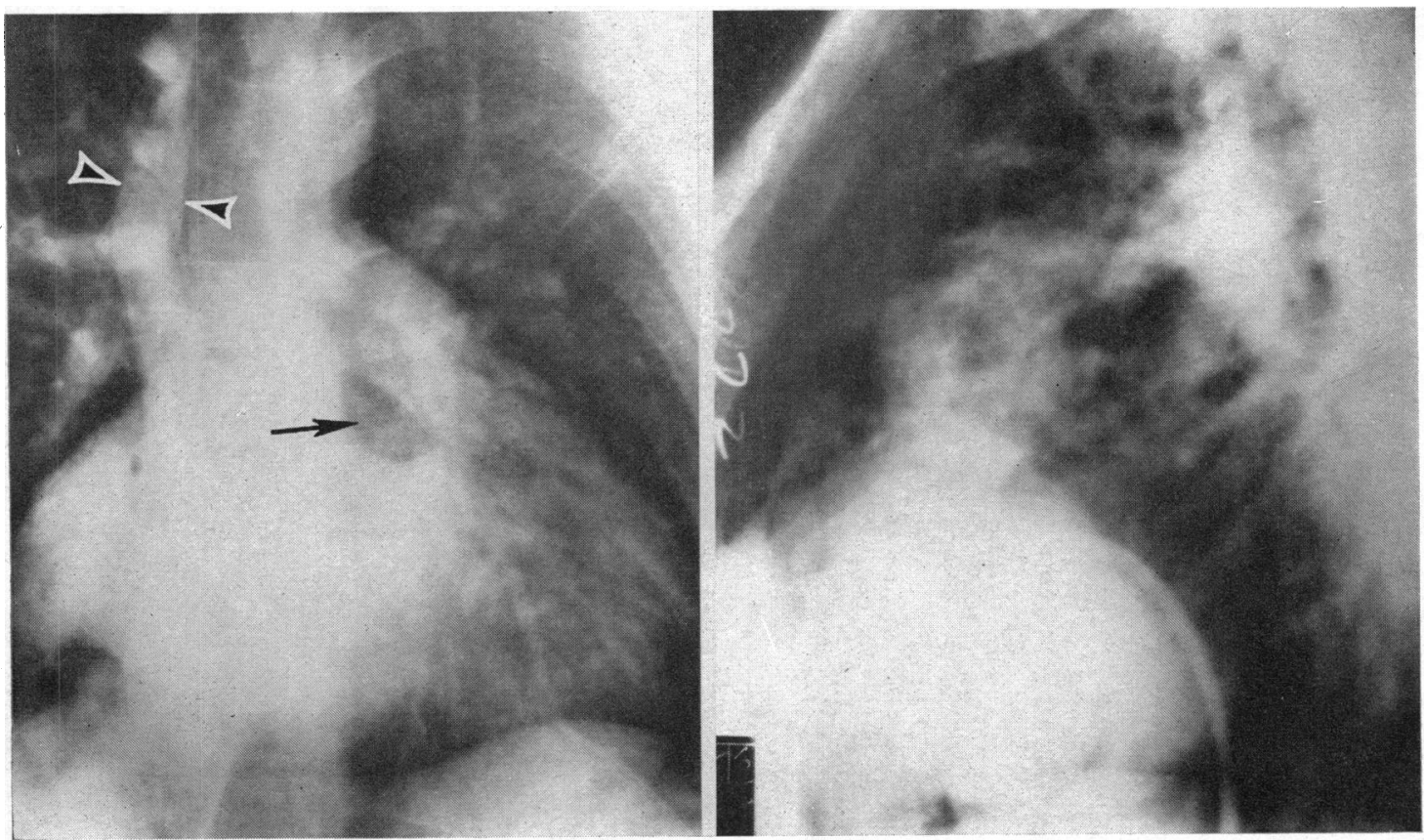

Fig. 11.-Angiocardiogram, right atrial injection. Antero-posterior and lateral view of Case 5 with double outlet right ventricle with pulmonary stenosis. There is reflux into superior vena cava 4 . Prominent parietal band of crista is seen $\rightarrow$. There is complete overlap of vessels in the lateral projection.

in double outlet right ventricle with pulmonary stenosis. These findings are rare in the tetralogy of Fallot.

The plain chest radiograph in our patients with double outlet right ventricle with pulmonary stenosis does not provide any specific criteria to aid in the diagnosis. The pronounced right ventricular enlargement in 3 patients is to be expected. The "normal" peripheral pulmonary arterial vasculature in 3 patients who had not had a previous subclavian-pulmonary artery anastomosis was an unexpected finding. Our experience is at variance with the larger group of patients reported by Mehrizi (1965). All 18 of the patients with double outlet right ventricle with pulmonary stenosis reported by him had pulmonary oligæmia. In addition, 4 had a right-sided aorta. All our patients had a left-sided aorta. His series, however, includes very few angiocardiograms, and the report stresses the necropsy findings. The wide spectrum of appearances of the plain chest film in the tetralogy of Fallot is well known. It is not surprising, therefore, that the chest radiographs in our patients did not yield any specific points to aid in the differentiation of double outlet right ventricle with pulmonary stenosis from the tetralogy of Fallot.

The clinical criteria, cardiographic, or radiological findings discussed above should demand further investigation of the condition by cardiac catheterization and angiocardiography. On cardiac catheterization the suggestive points are: an increase in the oxygen saturation in the right ventricle as compared with the right atrium in a cyanosed patient, and inability to introduce the catheter into the pulmonary artery. The increase in oxygen saturation from right atrium to right ventricle, though noted in some acyanotic patients with the tetralogy of Fallot, does not commonly occur in cyanotic patients with the tetralogy of Fallot. Angiocardiography has an important place in the diagnosis of double outlet right ventricle with pulmonary stenosis and in its differentiation from the tetralogy of Fallot. It became apparent on reviewing the 120 patients with the tetralogy of Fallot that the more specific angiocardiographic appearances associated with tetralogy of Fallot are readily identifiable. Nevertheless, the patients with tetralogy of Fallot in whom there was marked aortic override of the ventricular septum could be confused with the condition of double outlet right ventricle with pulmonary stenosis (Fig. 8).

Even the necropsy diagnosis may be difficult (Neufeld et al., 1961 a, b). The discontinuity of the mitral and aortic valves described in necropsy 
specimens of double outlet right ventricle with pulmonary stenosis (Carey and Edwards, 1965) cannot be depicted angiocardiographically.

We have used several angiocardiographic criteria in the diagnosis of double outlet right ventricle with pulmonary stenosis and its differentiation from tetralogy of Fallot. That both great vessels should opacify directly from the right ventricle is selfevident. Following the description of the parietal band by Carey and Edwards (1965), we confirmed that the parietal band of the crista supraventricularis was enlarged and clearly identifiable in the antero-posterior view in the 5 patients considered to have double outlet right ventricle with pulmonary stenosis (Fig. 1, 2, 7, 10, and 11); it is seen as a wide tongue of non-opacified tissue lying medial to the infundibulum of the right ventricle. Despite its size, it could not be visualized on the lateral projection. By contrast, in the anterior view the parietal band is usually a slender tongue of nonopacified tissue in a typical example of the tetralogy of Fallot.

It might be expected that the parietal band would be more prominent during right ventricular systole but this was not always the case. Although it was a striking feature throughout the cardiac cycle in Case 3 (Fig. 1), in others this structure was sometimes seen better in one or other phase of the cardiac cycle.

A relatively high position of the aortic semilunar valve was seen in 4 out of 5 patients (see Table II). Although 3 out of 5 (Cases 1,2, and 5) had the aortic and pulmonary semilunar valves in the same horizontal plane in the antero-posterior and lateral projection, this localization is somewhat of an approximation, since the levels of the valve rings vary during the cardiac cycle. Also, valve ring levels are not always of value in differentiating double outlet right ventricle with pulmonary stenosis from the tetralogy of Fallot, since we have seen several patients with the latter condition and relatively high position of the aortic valves, but without extreme aortic override. This aspect has been previously discussed by Carey and Edwards (1965) in double outlet right ventricle with and without pulmonary stenosis. The fact that the aorta overrides the septum to such a degree that it arises wholly from the right ventricle may be the explanation. Perhaps the high position is related to the fact that the right ventricle has a distinct outflow tract and so raises the root of the aortic valve. In support of this view is the fact that the aortic valve is high in transposition and corrected transposition of the great arteries (Fig. 9).

The ascending aorta was seen to point inferiorly and forward in all 5 patients considered to have double outlet right ventricle with pulmonary stenosis. This was seen in a sufficient number of patients with the tetralogy of Fallot to be of doubtful differential value by itself.

The ratio of the width of the pulmonary artery to the width of the aorta varied from 0.7 to 0.9 . This contrasted with a group of 12 patients typical of the tetralogy of Fallot, in whom the mean ratio was 0.5 on the antero-posterior projections. Smith et al. (1965) gave similar values in 21 patients with the tetralogy of Fallot who had had surgical correction. Of 31 patients, 21 had a ratio of pulmonary artery width to aortic width varying bebetween 0.3 and 0.6 , as measured at operation. The ratio for the remainder was between 0.7 and $1 \cdot 0$. The greater relative width of the aorta to the pulmonary artery in the tetralogy of Fallot is well known. It is uncertain whether this ratio will prove to be of value for diagnosing double outlet right ventricle with pulmonary stenosis.

The aorta never opacified prior to the pulmonary artery after right ventricular injection, but the relative sequence of great vessel opacification is merely a reflection of the higher resistance offered by the systemic circulation over that offered by the pulmonary stenosis.

Engle et al. (1963) has classified the double outlet right ventricle according to whether the ventricular septal defect was subaortic or subpulmonary, but exact timing of great vessel opacification was of no help in making this subdivision. In only one of our series (Case 3 ) could the site of the ventricular septal defect be exactly identified: the catheter passed from the right ventricle through the ventricular septal defect which could, therefore, be seen to be infracristal (Fig. 1).

In double outlet right ventricle the left ventricle can only empty its blood into the right ventricle via the ventricular septal defect. There is, therefore, a left-to-right shunt at ventricular level, which is present irrespective of the presence of severe pulmonary artery obstruction. This situation is fundamentally different from the tetralogy of Fallot with cyanosis at rest, where the dominant shunt is right to left. In only one patient was the left ventricle opacified initially (before recirculation), against the current of the left-to-right shunt. In this patient the catheter had been passed from the right ventricle to lie in the ventricular septal defect pointing into the left ventricle. The expected area of negative contrast in the right ventricle due to unopacified blood coming from the left ventricle was not seen in any patient. This is not entirely unexpected, since the ventricular septal defect opens high into the outflow tract of the right ventricle involved by pulmonary stenosis. There was no patient in 
this small group with right-sided aorta, though Mehrizi (1965) described 4 such cases.

Steinberg and Engle (1965) strongly support the use of left ventricular angiocardiography to differentiate double outlet right ventricle with pulmonary stenosis from the tetralogy of Fallot. These authors feel that in the left anterior oblique projection the origin of the aorta from the right ventricle can be differentiated from the aortic override of the tetralogy of Fallot, since the ventricular septum is seen end-on. Since double outlet right ventricle with pulmonary stenosis clinically simulates the tetralogy of Fallot, and as the tetralogy of Fallot is by far the commoner anomaly it seems likely that most patients will continue to be studied by right ventricular catheterization and angiocardiography. In the tetralogy of Fallot the essential information needed is the internal anatomy and hæmodynamics of the right ventricle. A diagnosis of double outlet right ventricle with pulmonary stenosis can be made from a right-sided angiocardiographic study alone. The additional information to be gained from a further left-sided angiocardiographic examination would have to be an individual and clinical decision for each patient. Left ventricular angiocardiography would further entail a transseptal or transaortic approach, since a catheter cannot always be made to pass through the ventricular septal defect. This entails an additional hazard. Carey and Edwards (1965) used the position of catheters in the right and left ventricle to show that both aortic and pulmonary artery valves lie in the same coronal plane. Although our series does not include any left ventricular angiocardiogram, in one patient the catheter passed from the right ventricle through the ventricular septal defect to opacify the left ventricle (Fig. 1).

Our series did not include any patients with moderator band hypertrophy. Cheng (1962) described the necropsy findings in a patient with double outlet right ventricle without pulmonary stenosis, in whom the right ventricle was partly divided into two compartments by a hypertrophied moderator band projecting into the cavity of the right ventricle from.below, while a thickened muscle mass (presumably the parietal band) did so similarly from above. Since this patient died during angiocardiography, adequate films to show the moderator band were not available.

\section{CoNCLUSION}

Double outlet right ventricle with pulmonary stenosis and the tetralogy of Fallot may be similar clinically and angiocardiographically, but their surgical treatment differs. An important anatomical difference, the discontinuity of aortic and mitral valve rings in double outlet right ventricle, is not apparent on angiocardiograms. Angiocardiography is an essential preliminary to surgery in cyanosed patients, and in order to give to the cardiologists and surgeons prior warning of the condition the following scheme is suggested. All patients with a ventricular defect, pulmonary stenosis, complete overlapping of the proximal ascending aorta and pulmonary artery, and an ascending aorta pointing inferiorly and forward in the lateral projection, should be considered as potential examples of double outlet right ventricle. In those in whom there is prominence of the parietal band in the antero-posterior view but failure to visualize a crista in the lateral view, the diagnosis should be regarded as one of double outlet right ventricle with pulmonary stenosis until disproved. If this turns out to be correct at cardiotomy, the mistake of closure of the ventricular septal defect as part of the total correction of tetralogy of Fallot will not have been made. Instead, the appropriate sling operation (McGoon, 1961; Kiklin et al., 1964; Redo et al., 1963) can be performed. If exploratory cardiotomy, however, shows the anatomy to be that of the tetralogy of Fallot, then total correction with closure of the ventricular septal defect can be carried out safely. In our view, patients with double outlet right ventricle with pulmonary stenosis who have only mild cyanosis and few symptoms should not have radical surgical correction of this defect, because of the difficulties involved. By contrast, patients with the tetralogy of Fallot usually require radical correction. In the presence of severe cyanosis due to double outlet right ventricle with pulmonary stenosis, closed infundibular resection or a systemic pulmonary artery shunt operation may be useful palliative procedures.

\section{SUMMARY}

Earlier reports on patients with double outlet right ventricle and pulmonary stenosis are reviewed, and the findings in five additional patients with this condition are reported.

Double outlet right ventricle with pulmonary stenosis is an uncommon lesion. Patients with this condition are with difficulty differentiated from those with tetralogy of Fallot. The differentiation is important since the surgical treatment of the two disorders is very different. In double outlet right ventricle with pulmonary stenosis the second sound may be maximal at the second space along the left sternal border. In tetralogy of Fallot this sound is loudest at the fourth space. A left-to-right ventricular shunt is infrequent in cyanosed patients with 
tetralogy of Fallot but is essential in patients with double outlet right ventricle with pulmonary stenosis. Angiocardiography shows that both great vessels originate from the right ventricle, and lie in the same coronal plane. The aortic valve is higher than normal and points downwards and anteriorly rather than downwards and posteriorly, as seen in most patients with tetralogy of Fallot. The parietal band of the crista supraventricularis is prominent in the antero-posterior projection but obscured in the lateral projection; this is in contrast to the findings in the tetralogy of Fallot.

\section{REFERENCES}

Braun, K., de Vries, A., Feingold, D. S., Ehrenfeld, N. E., Feldman, J., and Schorr, S. (1952). Complete dextroposition of the aorta, pulmonary stenosis, interventricular septal defect, and patent foramen ovale. Amer. Heart f., 43, 773.

Carey, L. S., and Edwards, J. E. (1965). Roentgenographic features in cases with origin of both great vessels from the right ventricle without pulmonary stenosis. Amer. 7. Roentgenol., 93, 269.

Cheng, T: O. (1962). Double outlet right ventricle: diagnosis during life. Amer. F. Med., 32, 637.

Coelho, E., Paiva, E., Nunes, A., and Amram, S. S. (1963). Origin of both great vessels from the right ventricle with pulmonary stenosis: Angiocardiographic findings. Amer. Heart F., 65, 766.

Engle, M. A., Holswade, G. R., Campbell, W. G., and Goldberg, H. P. (1960). Ventricular septal defect with transposition of aorta masquerading as acyanotic ventricular septal defect. Circulation, 22, 745.

-, Steinberg, I., Lukas, D. S., and Goldberg, H. P. (1963). Acyanotic ventricular septal defect with both great vessels from the right ventricle. Amer. Heart F., 66, 755.

Kirklin, J. W., Harp, R. A., and McGoon, D. C. (1964). Surgical treatment of origin of both vessels from right ventricle, including cases of pulmonary stenosis. $\mathcal{f}$. thorac. cardiovasc. Surg., 48, 1026.
Lauer, R. M., DuShane, J. W., and Edwards, J. E. (1960). Obstruction of left ventricular outlet in association with ventricular septal defect. Circulation, 22, 110.

Levy, M. J., DeWall, R., Elliott, L. P., and Cuello, L. (1962). Origin of both great arteries from the right ventricle and pulmonary stenosis. Apropos case successfully corrected. Dis. Chest, 42, 372.

McGoon, D. C. (1961). Origin of both great vessels from the right ventricle. Surg. Clin. N. Amer., 41, 1113.

Mehrizi, A. (1965). The origin of both great vessels from the right ventricle. Bull. Fohns Hopk. Hosp., 117, 75.

Mirowski, M., Mehrizi, A., and Taussig, H. B. (1963). The electrocardiogram in patients with both great vessels arising from the right ventricle combined with pulmonary stenosis. Circulation, 28, 1116.

Morgan, J., Pitman, R., Goodwin, J. F., Steiner, R. E., and Hollman, A. (1962). Anomalies of the aorta and pulmonary arteries complicating ventricular septal defect. Brit. Heart f., 24, 279.

Nadas, A. S. (1963). Pediatric Cardiology, 2nd ed., p. 703. Saunders, Philadelphia.

Neufeld, H. N., DuShane, J. W., and Edwards, J. E. (1961a). Origin of both great vessels from the right ventricle. II. With pulmonary stenosis. Circulation, 23, 603.

$\longrightarrow,-$, Wood, E. H., Kirklin, J. W. and Edwards, J. E. (1961b). Origin of both great vessels from the right ventricle. I. Without pulmonary stenosis. Circulation, 23, 399.

Redo, S. F., Engle, M. A., Holswade, G. R., and Goldberg, H. P. (1963). Operative correction of ventricular septal defect with origin of both great vessels from the right ventricle. $\mathcal{F}$. thorac. cardiovasc. Surg., 45, 526.

Smith, D. R., Effat, H., Hamed, M. A., and Omeri, M. Al (1965). Radiological and surgical anatomy in tetralogy of Fallot and the effect on surgical prognosis. Brit. Heart F., 27, 604.

Steinberg, I., and Engle, M. A. (1965). Angiocardiographic diagnosis of both great vessels originating from right ventricle: report of thirteen acyanotic patients. Amer. f. Roentgenol., 94, 45.

Witham, A. C. (1957). Double outlet right ventricle: a partial transposition complex. Amer. Heart f., 53, 928. 